\title{
South Atlantic Anomaly Seasonal Seismicity during Two Solar Cycles
}

\author{
Marilia Hagen', Anibal Azevedo ${ }^{2}$ \\ ${ }^{1} 1262$ Yellowwood Lake Road, Nashville, USA \\ ${ }^{2}$ Faculdade de Ciências Aplicadas da Unicamp, Limeira, São Paulo \\ Email: marhagen@indiana.edu, anibal.azevedo@fca.unicamp.br
}

How to cite this paper: Hagen, M. and Azevedo, A. (2020) South Atlantic Anomaly Seasonal Seismicity during Two Solar Cycles. Open Journal of Earthquake Research, 9, 307-322.

https://doi.org/10.4236/ojer.2020.94018

Received: May 22, 2020

Accepted: July 26, 2020

Published: July 29, 2020

Copyright $\odot 2020$ by author(s) and Scientific Research Publishing Inc. This work is licensed under the Creative Commons Attribution International License (CC BY 4.0).

http://creativecommons.org/licenses/by/4.0/ (c) (i) Open Access

\begin{abstract}
The aim of this paper is to investigate the effects of Solar cycles and season fluctuations on earthquakes, in a location named South Atlantic anomaly. The area used herein is delimited $0 \mathrm{~N},-50 \mathrm{~S}, 40 \mathrm{E},-90 \mathrm{~W}$, and is the region with the Earth's lowest magnetic field, which allows a higher number of ionized particles to reach the ionosphere. The period chosen is 1996-2018, comprising two Solar Cycles and the respective solar maxima in 2000 and 2014. The first results pointed out that occurrences of swarm location depending from the depth search. Shallow earthquakes developed swarms near the shorelines and deep depth inland. A mathematical model was developed to statistically evaluate the changes in the earthquakes increases. The outcome resolutions showed Summer and Fall are the most important seasons for tremors in this region. The period analyzed have an extended solar minimum occurred 2003-2010, we analyzed the evolution of earthquakes occurrences under the South Atlantic anomaly.
\end{abstract}

\section{Keywords}

South Atlantic Anomaly, Solar Cycles, Seasons, Earthquakes

\section{Introduction}

Earth is surrounded by the dipolar or almost-spherical magnetic field, and the Sun sends electromagnetic radiation plus ionized particles towards the Earth and reaches the magnetosphere. Those particles penetrate the poles or other regions of the terrestrial magnetosphere and enter the atmosphere. The Earth's magnetic field configuration allows the trapping and distribution of energized ionized particles in different layers. The magnitude variation of this field varies from 30,000 $\mathrm{nT}$ at the equator to $50,000 \mathrm{nT}$ at the poles [1]. 
The South Atlantic Anomaly (SAA) is a low magnetic field area that spans from east of Africa over the Atlantic Ocean and is centered on South America (See Figure 1). This weak magnetic field region has expanded over time and has also moved westward; it is linked with the geomagnetic field distribution. The SAA is characterized by a lower magnetic intensity and is a location where the inner radiation belts are closest to Earth's surface. The movement of this anomaly over South America was found as $0.06 \mathrm{~N} / \mathrm{yr}$. and $0.28 \mathrm{~W} / \mathrm{yr}$ [2].

The energetic particles captured by the geomagnetic field can reach lower altitudes, forming a high radiation region. The SAA, when compared to other locations, indicates a more significant number of energetic particles. The eccentric dipole is currently offset from Earth's center by about $550 \mathrm{~km}$ in a path approximately $22^{\circ} \mathrm{N}, 140^{\circ} \mathrm{E}$. This distance is steadily increasing, and the location of the eccentric dipole center is drifting westward and slightly northward. In the antipodal route, which corresponds to the location of the SAA, the drift shells get closer to Earth's surface and move mainly westward and slightly southward. The SAA is approximately centered over Sao Paulo (Brazil) [3].

Thermospheric density is directly correlated with the Sun's activity due to heating driven by Solar radiation and shows the same time evolution as the Solar Cycle. The density of particles increases at high altitudes as the atmosphere expands during Solar maxima, which leads to more frequent collisions between the trapped energetic protons and atmospheric atoms. The trapped protons are depleted during the higher activity of the Solar Cycles.

Shaeffer et al. [4] showed that the particle hit intensity in the region was anticorrelated with the Solar activity. If there are years of high solar activity, the radiation intensity is lower, while during quiet solar years, the radiation intensity is more powerful. Their data implied the strong solar wind from the Sun sweeps out more low-energy galactic cosmic rays, while the Sun's smooth winds let more in. The peak of SAA intensity occurs a bit later than the last year of the solar minimum. Their data connected sunspot number minimum occurring in 2009 with the peak of SAA intensity. According with them, Geomagnetic storms charge particles that are precipitated along the magnetic field lines in the auroral zone and also induce photometer counters. The SAA does not remain in a fixed

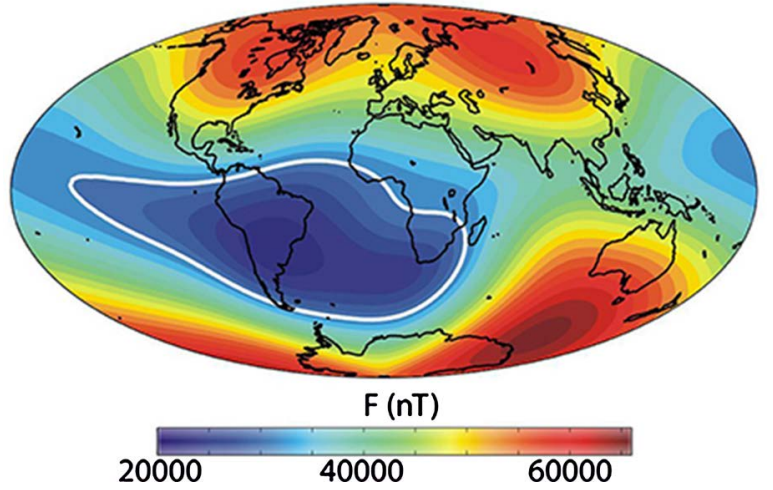

Figure 1. South Atlantic anomaly region and magnetic field magnitudes in nanoteslas. 
geographic location; instead, it tends to drift in a mostly west northeast direction.

McCracken et al. [5] studied the period 2004 to 2016 that showed particle hit intensity was anticorrelated with solar activity. The authors compared three former minimum named the three Grand Minima, the Spoerer, Maunder and Dalton minima the long sunspot minimum of 2006-2009. The heliospheric magnetic field strength (3.9 nT) observed in 2009 was much more significant than the peak values of $2.0-2.9 \mathrm{nT}$ found for the three Grand Minima.

The evolution of the SAA particle flux can be seen as the result of two main effects: 1) the secular variation of Earth's core magnetic field and 2) the modulation of the density of the inner radiation belts during the solar cycle, as a function of the L value that characterizes the drift shell where charged particles are trapped [6]. The unusual spatial characteristics for the area indicate that it would be essential to determine if those disturbances would be necessary for the earthquake's evolution. It was found that during the solar minima 2006-2010, there was an indication of higher earthquake activity in the region.

We also search for the seasonality earthquake variation in the two setups, one for all the tremors that occurred in the area, and another for the depths $\geq 200$ $\mathrm{km}$. The first group (all depths) identified earthquakes swarm locations at shorelines in Southern Pacific. The ones with depths $\geq 200 \mathrm{~km}$ occurring in a different location inland. Both scenarios, indicated tremors in the region occurring most during Summer and Fall.

The paper is divided into a brief study of a swarm of earthquakes around the southern Pacific subduction under South America, for all events and deep-depth earthquakes. Catalogs and data for earthquakes are found in [7] [8]. Data for Solar Cycles are found in [9]. Our research considers earthquakes with $M \geq 3$ since, in a past paper, we showed that lower magnitudes can be from an anthropogenic origin [10]. We included a section with a dependence of events into depths in this area where anomaly occurrences were found in [10] [11] [12].

To study the development of these events and parameters, it is necessary to employ a statistical, mathematical model using the number of earthquakes specified, in years and months, for two cycles.

\section{Swarm of Earthquakes around South America Anomaly}

The following Table 1 shows the locations under the South Atlantic anomaly with the occurrence of great swarms in the period 1996-2018. Table 1 has 16 swarm events, which most occurrences were in the Fall, Summer/Fall, or Fall/ Winter. The following years, between 2003-2010, present the highest number of swarms and also correspond to the year of quiet solar activity [5]. In 2006, the swarm had two distinct periods: Fall/Winter and Winter; there were 1118 total events. Such results coinciding with [5] attribute maximum solar radiation during the solar minima years (See Figure 2).

It appears that Fall drives most of the swarm earthquakes from around the 
Table 1. Data swarms for earthquakes period 1996-2019, all depths.

\begin{tabular}{|c|c|c|c|}
\hline Year & Anomaly & Coordinates & Swarm region (number of events) \\
\hline 1998 & Jul-Aug & $-27.64 \mathrm{~N},-37.47 \mathrm{~S},-66.25 \mathrm{E},-74.85 \mathrm{~W}$ & Valparaiso-Concepcion (Chile)-324 \\
\hline 2001 & Apr & $-18.94 \mathrm{~N},-40.05 \mathrm{~S},-60.30 \mathrm{E},-74.36 \mathrm{~W}$ & Chile coast- 294 \\
\hline 2001 & Jun & $-14.13 \mathrm{~N},-37.17 \mathrm{~S},-64.39 \mathrm{E},-75.28 \mathrm{~W}$ & Peru/Bolívia-238 -Chile Coast-111 \\
\hline 2001 & Oct & $-18.96 \mathrm{~N},-36,58 \mathrm{~S},-64.26 \mathrm{E},-77.97 \mathrm{~W}$ & Northern/Southern Chile-119 \\
\hline 2001 & Dec & $-26.81 \mathrm{~N},-37.70 \mathrm{~S},-65.71 \mathrm{E},-73.09 \mathrm{~W}$ & Northern/Southern Chile-372 \\
\hline 2002 & Jan-Apr & $-2.07 \mathrm{~N},-41.75 \mathrm{~S},-63.63 \mathrm{E},-82.79 \mathrm{~W}$ & Near coast Ecuador/ South Argentina-1051 \\
\hline 2003 & Apr-Jun & $-18.89 \mathrm{~N},-39.30 \mathrm{~S},-63.75 \mathrm{E},-73.07 \mathrm{~W}$ & Near Coast Chile, S. Chile/Arg border-1273 \\
\hline 2005 & May-Jun & $-13.48 \mathrm{~N},-41.43 \mathrm{~S},-64.26 \mathrm{E},-77.27 \mathrm{~W}$ & Central Peru, Near Coast Chile- 470 \\
\hline 2006 & Apr-May & $-25.60 \mathrm{~N},-36.21 \mathrm{~S},-67.76 \mathrm{E},-72.58 \mathrm{~W}$ & Chile/ Arg border, Central Chile- 562 \\
\hline 2006 & Jul-Aug & $-27.65 \mathrm{~N},-37.40 \mathrm{~S}, 67.7 \mathrm{E},-72.5 \mathrm{~W}$ & Chile Coast, Central Chile-556 \\
\hline 2007 & May & $-18 \mathrm{~N},-38.15 \mathrm{~S},-62.20 \mathrm{E},-74.68 \mathrm{~W}$ & North/Southern Chile-289 \\
\hline 2007 & Jul-Aug & $-12.33 \mathrm{~N},-16.08 \mathrm{~S},-74.8 \mathrm{E},-78.05 \mathrm{~W}$ & Peru coast-South/Central Chile-737 \\
\hline 2010 & Feb-Apr & $-32.27 \mathrm{~N},-39.45 \mathrm{~S},-70.37 \mathrm{E},-75.38 \mathrm{~W}$ & Coast Central Chile-1531 \\
\hline 2014 & Mar-Apr & $-32.27 \mathrm{~N},-39.45 \mathrm{~S},-66.46 \mathrm{E},-75.38 \mathrm{~W}$ & Coast Central Chile-618 \\
\hline 2015 & Sep-Nov & $-27.75 \mathrm{~N},-37.57 \mathrm{~S},-68.59 \mathrm{E},-75.18 \mathrm{~W}$ & Coast and off coast Central Chile-923 \\
\hline 2017 & Apr & $-19.29 \mathrm{~N},-39.35 \mathrm{~S},-65.88 \mathrm{E},-75.73 \mathrm{~W}$ & Near Coast Central and North Chile, off coast-202 \\
\hline
\end{tabular}

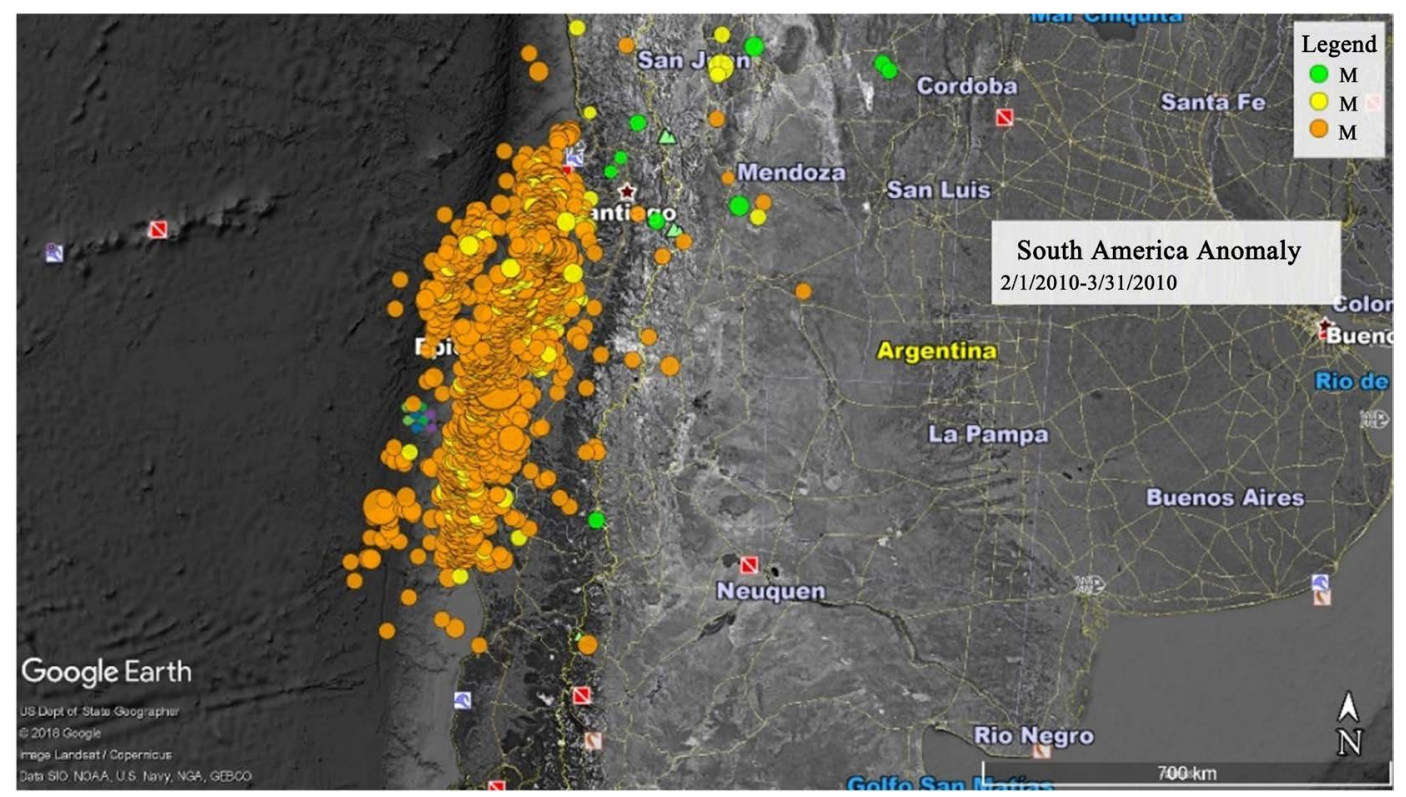

Figure 2. The location of South America with the highest number of earthquakes clusters at the Chilean coast (all depths considered).

South Pacific shorelines to South America. The clusters were found in the same region as the entire Chile coast and Central Chile. The location is defined by $-20.20 \mathrm{~N},-39.89 \mathrm{~S},-69.43 \mathrm{E},-74.70 \mathrm{~W}$, with the most in-depth event in the area at $213 \mathrm{~km}$. 
These results indicate a correlation between the earthquakes and the Solar minimum. Figure 2 shows the location in South America, where the clusters appeared in the maximum number of happenings.

\section{Swarm of Earthquakes in South America for Deep Earthquakes}

Table 2 exhibits the features for earthquakes with a depth below $200 \mathrm{~km}$. First column is the year of occurrence, then the month, coordinates and swarm regions, and the number of occurrences. Observe that the swarms here are fewer events than those included in Table 1. Also, the location of these events is intraplate around Brazil and borders with other South American countries. In this case, there are the maximum number of earthquakes in 2017 (88 tremors) and 2018 (48 shocks).

Deeper earthquakes indicate that the lithosphere is uneven into these depths and must play a strict rule for the occurrences [10] [12] [13].

The years with more events were 2017 (Fall/Winter), 2018 (Fall/Winter), and the region reached was the same for both years: Chile/Argentina border, Southern Bolivia, Jujuy, and Salta (Argentina).

Figure 3 shows a rare circumstance of the swarm reaching the highest number of occurrences in South America. The data in the chart is from November 2015. There is a complete absence of events due to the Solar maxima, 2000 and 2014, and the highest number of clusters that happened in the period mentioned as solar minimum. Both Table 1 and Table 2 indicate an anomaly number of earthquakes during Fall or Fall/Winter.

The next section shows the data and techniques for analysis of the earthquakes data set.

Table 2. Shows data swarm of quakes for depths $\geq 200 \mathrm{~km}$.

\begin{tabular}{cccc}
\hline Year & Anomaly & Coordinates & Swarm region (number of events) \\
\hline 1997 & Mar -Fall & $-7.76 \mathrm{~N},-10.49 \mathrm{~S},-69.96 \mathrm{E},-72.96 \mathrm{~W}$ & Western Brazil, Peru border (3) \\
2001 & Apr-Fall & $-16.21 \mathrm{~N},-34.23 \mathrm{~S},-61.14 \mathrm{E},-72.04 \mathrm{~W}$ & Jujuy-Argentina, Southern Bolivia, Chile/Bolivia (20) \\
2005 & Mar-(Fall) & $-16.94 \mathrm{~N},-27.78 \mathrm{~S},-60.58 \mathrm{E},-68.38 \mathrm{~W}$ & Jujuy-Argentina, Chile/Bolivia, Peru/Brazil border (17) \\
2007 & May-(Fall) & $8.49 \mathrm{~N},-52.21 \mathrm{~S},-14.03 \mathrm{E},-119.15 \mathrm{~W}$ & Chile/Argentina, Western Brazil, S. Peru, Jujuy (13) \\
2007 & Aug-winter & $-18.07 \mathrm{~N},-27.15 \mathrm{~S},-64.48 \mathrm{E},-68.03 \mathrm{~W}$ & S Bolívia, Argentina border, Jujuy Argentina (13) \\
2010 & Feb-Summer & $-18.07 \mathrm{~N},-25.15 \mathrm{~S},-64.36 \mathrm{E},-69.46 \mathrm{~W}$ & Chile/Argentina, South Bolivia, Jujuy, (15) \\
2015 & Feb -Summer & $-17.6 \mathrm{~N},-26.74 \mathrm{~S},-63.86 \mathrm{E},-68.15 \mathrm{~W}$ & (Jujuy, Salta) Argentina, Southern Bolivia (13) \\
2015 & Nov-Spring & $-7.58 \mathrm{~N},-11.39 \mathrm{~S},-69.56 \mathrm{E},-72.33 \mathrm{~W}$ & Peru/Brazil border, Western Brazil (19) \\
2016 & Oct-Nov Spring & $-18.07 \mathrm{~N},-26.36 \mathrm{~S},-65 \mathrm{E},-68 \mathrm{~W}$ & Chile/Argentina border, South Bolivia (23) \\
2017 & May-Jul Fall-Winter & $-18.07 \mathrm{~N},-26.36 \mathrm{~S},-65 \mathrm{E},-68.6$ & Chile/Argentina border, S.Bolivia, Salta, Jujuy, Mendoza (65) \\
2017 & Dec Summer & $-18.54 \mathrm{~N},-25.06 \mathrm{~S},-65.37 \mathrm{E},-68.97 \mathrm{~W}$ & Bolivia (Central, South), Jujuy, Salta, Mendoza (Argentina) (13) \\
2018 & Apr-Jul Fall-Winter & $-18.07,-27.15 \mathrm{~S},-64.48 \mathrm{E},-69.03 \mathrm{~W}$ & Jujuy, Salta, Chile/Argentina border, South Bolivia (41) \\
2019 & Dec-Summer & $-19.12 \mathrm{~N},-25.30 \mathrm{~S},-64.13 \mathrm{E},-70.1 \mathrm{~W}$ & Chile/Argentina, Jujuy (11)
\end{tabular}




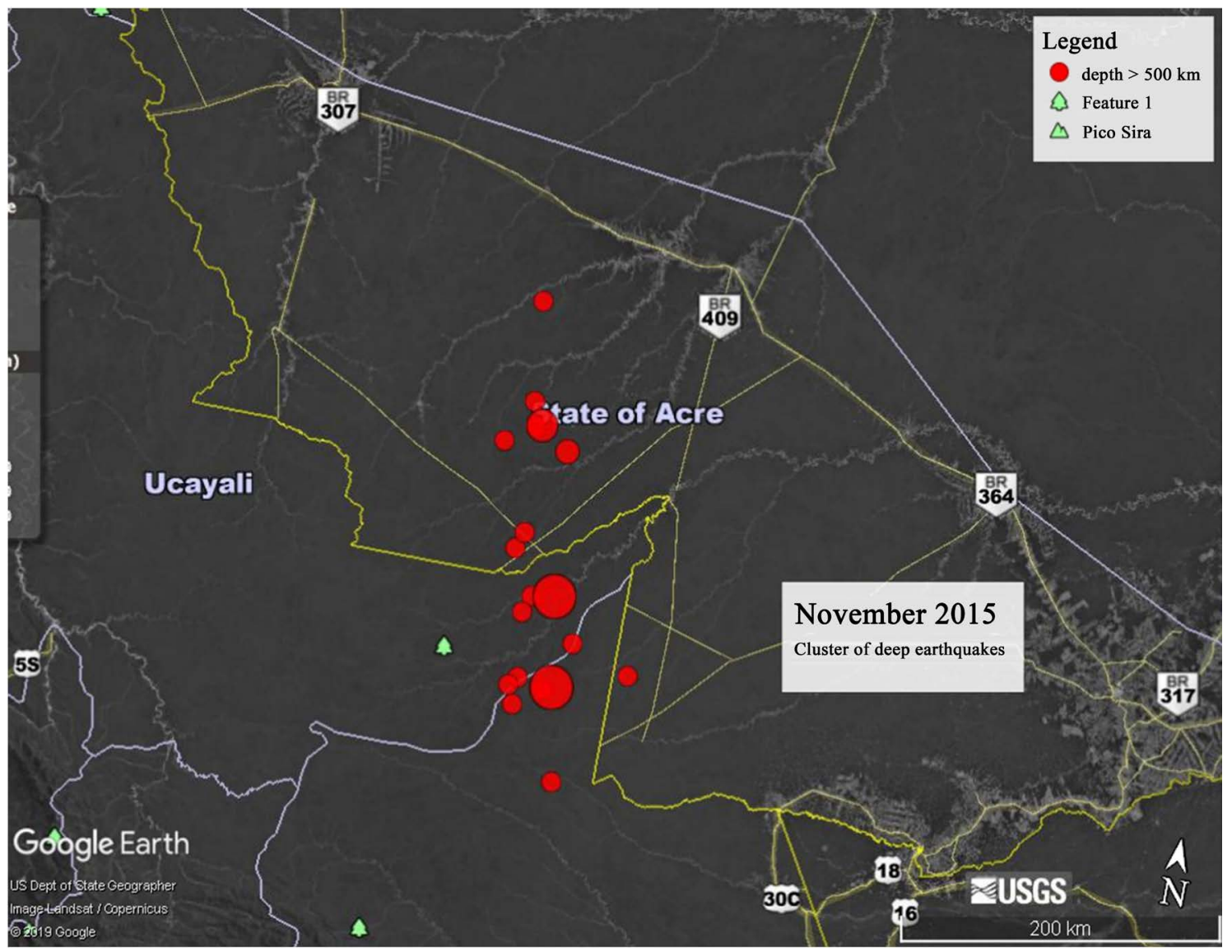

Figure 3. Occurrence of cluster for deepest earthquakes in 2015, SAA.

\section{Data, Techniques for Analysis}

This paper is focused on a region that has earthquakes rising in different locations; part of them are at the Southern Pacific side, part in the Atlantic Ridge, and a few earthquakes in Africa. The coordinates are $0 \mathrm{~N},-50 \mathrm{~S}, 40 \mathrm{E},-90 \mathrm{~W}$. The seasons in the Southern Hemisphere are in Table 3. The catalogs for earthquakes are from USGS and IRIS, both offering different approaches, and only USGS can map the region and display the data [7] [8].

\subsection{Mathematical Method}

The following is our method to determine if earthquakes increase, decrease, or remain constant in each region and depth: First, we collected the data for shallow earthquakes occurring at the South Atlantic anomaly; the dimensions for depth is $d \leq 200 \mathrm{~km}$. Assessed events are with typical magnitudes of $M \geq 3$ during the period 1996-2018. This defines the last Solar Cycles 23 and 24, the year maxima are 2000 and 2014, and the minima are 1996 and 2008. Our data offers the year, month, and number of earthquakes for each. The average is found by dividing the total amount per month by 22 , which is the total number of years in the period. The tables constructed will show the year, month, and correlated number of events, on average. 
Table 3. Seasons in the southern hemisphere.

\begin{tabular}{cc}
\hline South Hemisphere & Range \\
\hline Spring & Sept 1-Nov 30 \\
Summer & Dec 1-Feb 28 \\
Fall & March 1-May 30 \\
Winter & Jun 1-Aug 31 \\
\hline
\end{tabular}

\subsection{Construction of Tables and Plots}

The data set comprises earthquakes recorded during the period 1996-2018.

The raw data shows that several months had earthquake event anomalies, either positive or negative. It shows two types of anomalies: positive and negative. Positive anomalies are when the number of events is above average, and negative when the number of earthquakes is below average. The ones we can reveal are the positive anomalies.

Our plots are most intended to show how Solar Cycles and seasonal changes can relate to event variations. The South Atlantic Anomaly has a tight connection with geomagnetic storms which leans toward a region with a weaker magnetic field. The raw data is impossible to be studied, and it is necessary to adjust this data mathematically to find any valuable variance or connection with the described factors above.

The data values are described by year and month and they are collected for all depths during these 22 years.

$$
\sum_{n 0}^{n n} Y n=y n 0+y n 1+\cdots+y n n^{\prime}
$$

where $n=1996 \cdots 2018$, and $n^{\prime}$ is 22 years.

The mean is defined as

$$
\text { Mean }=A=\frac{\sum_{n 0}^{n n} Y n}{22}
$$

Data value - mean $=Y n^{\prime}$

If $Y n^{\prime}>A$, the value is greater than one during that year, and it means the number of earthquakes exceeds the average. It is divided by the number/average and it gives how much the events surpassed the standard. The results are discussed in the next section. On the other hand, if $Y n^{\prime}<A$, the number will be less than one during that year, demonstrating that the number of earthquakes was below average.

There are two kinds of possible anomalies in the data, positive and negative. The positive anomaly is a result that is higher than the average number considered as 1 . There is only one negative number found, -0.5 , and it means the number of events was half of the average.

For example, in Table 4, a negative anomaly appeared in January 2010, of -0.5 . This means was half of the average which is 1 , considering the given month and year. The positive anomalies are numbered above 1, for example. January 
Table 4. The evolution of earthquake events for all depths period 1996-2018.

\begin{tabular}{|c|c|c|c|c|c|c|c|c|c|c|c|c|}
\hline Year & Jan & Feb & Mar & Apr & May & Jun & Jul & Aug & Sep & Oct & Nov & Dec \\
\hline 1996 & 1.3 & 1.2 & 0.9 & 0.9 & 0.8 & 1 & 0.9 & 0.9 & 0 & 0 & 1.2 & 1 \\
\hline 1997 & 0.9 & 1 & 1.2 & 1.1 & 1 & 0 & 1.3 & 0.8 & 0.8 & 0.9 & 1.1 & 1 \\
\hline 1998 & 0.9 & 0 & 0.9 & 0.9 & 1 & 0.9 & 1.5 & 1.1 & 0.9 & 1 & 1 & 0.8 \\
\hline 1999 & 0.9 & 1.1 & 1.2 & 1.1 & 0.9 & 1.1 & 0.9 & 1.1 & 1 & 0.7 & 1 & -0.5 \\
\hline 2000 & 0 & 0.8 & 1.1 & 0.9 & 0.9 & 1.1 & 0 & 1.1 & 1 & 1 & 1 & 1 \\
\hline 2001 & 0.7 & 0.7 & -0.5 & 1.2 & 0.7 & 1.5 & 1.1 & 0.7 & 0.6 & 1.2 & 1.1 & 1.4 \\
\hline 2002 & 1.3 & 1.1 & 1.2 & 1 & 1 & 0.8 & 1 & 0.7 & 0.7 & 0.9 & 0.9 & 0.9 \\
\hline 2003 & 0 & 0.9 & 1.2 & 1.2 & 1 & 1.3 & 1.3 & 0.9 & 0.9 & 0.9 & 0.9 & 0.9 \\
\hline 2004 & 0.8 & 0 & 0.9 & 0.9 & 1.1 & 0.8 & 1 & 1.3 & 1.2 & 1 & 0.8 & 1.1 \\
\hline 2005 & 1 & 0 & 0.9 & 1.2 & 1.4 & 0.9 & 0.9 & 0.9 & 1 & 1.2 & 0.9 & 0.7 \\
\hline 2006 & 0.8 & 0 & 0.9 & 1.2 & 1.4 & 0.9 & 0.9 & 0.9 & 1 & 1.2 & 0.9 & 0.7 \\
\hline 2007 & 0.8 & 0 & 0.9 & 0.9 & 1.1 & 0 & 1 & 1.7 & 0.9 & 0.9 & 0.9 & 0.8 \\
\hline 2008 & 0.9 & 0.9 & 1 & 0.8 & 1.2 & 1.1 & 1.1 & 1 & 0.6 & 1 & 1.2 & 1.2 \\
\hline 2009 & 0.8 & 0.8 & 0.9 & 0.8 & 1.2 & 1.1 & 1 & 1 & 0.6 & 1 & 1.2 & 1.1 \\
\hline 2010 & -0.5 & 4 & 6 & 1.7 & 1.2 & 0.9 & 0.7 & 0.8 & 0.8 & 0 & -0.5 & -0.5 \\
\hline 2011 & 1.6 & 1.4 & 0.8 & 1 & 0.8 & 1.2 & 1 & 0.7 & 0.8 & 1.1 & 0.9 & 0.7 \\
\hline 2012 & 0.9 & 0.9 & 1 & 1.1 & 1.1 & 1 & 0.8 & 0.8 & 0.9 & 1 & 1.1 & 1 \\
\hline 2013 & 0.8 & 0.8 & 0.9 & 0.9 & 0.9 & 0.9 & 1.2 & 1 & 1.1 & 1.1 & 1.2 & 1.2 \\
\hline 2014 & 0.6 & -0.5 & 1.7 & 2.8 & 0.9 & 0.8 & 0.8 & 0 & 0 & 0.7 & 0.6 & 0 \\
\hline 2015 & 0.5 & 0.5 & 0.7 & -0.5 & -0.5 & 0.5 & -0.5 & -0.5 & 2.5 & 1.2 & 1.1 & 0.8 \\
\hline 2016 & 0.9 & 1.1 & 0.9 & 1.4 & 0.8 & 1.1 & 1.1 & 1 & 0.9 & 0.8 & 0.9 & 0 \\
\hline 2017 & 1 & 0.9 & 0.9 & 2 & 0.9 & 0.9 & 0.9 & 0.9 & 0.9 & 0 & 0.9 & 0.9 \\
\hline 2018 & 0.9 & 0.9 & 1 & 1.1 & 0.9 & 1 & 0.9 & 1 & 1.3 & 1 & 0.9 & 1 \\
\hline
\end{tabular}

2011, of 1.6. It means the number of earthquakes during this month and year was 0.6 above the average number 1 . The only negative anomaly allows with physical meaning is -0.5 ; anything lower could not be evaluated. Negative numbers below this value are regarded as zero variation for physical connotation.

Examining Table 4, in 2015, we observed four negative anomalies occurrencing during Fall and Winter and a peak in the Spring (Sept, Oct, Nov). However, 2015 is one year after a solar maximum in 2014. Table 5 shows the quakes with the deepest depth and displays similar behavior in 2015, but only positive anomalies for the seasons, especially during the Spring. Both Table 4 and Table 5 display the evolution of earthquakes by months.

\section{Discussion of Solar Cycles}

For this part of this study we use the calculations performed in Section 2 to search the variations in the earthquakes in the area defined by $0 \mathrm{~N},-50 \mathrm{~S}, 40 \mathrm{E}$, 
Table 5. Showing the results for depths $\geq 200 \mathrm{~km}$.

\begin{tabular}{|c|c|c|c|c|c|c|c|c|c|c|c|c|}
\hline Year & Jan & Feb & Mar & Apr & May & Jun & Jul & Aug & Sep & Oct & Nov & Dec \\
\hline 1996 & 0 & 1.3 & 1 & 1.1 & 0 & 1.3 & 1 & 0.9 & 1 & 0 & -0.5 & 0.9 \\
\hline 1997 & 1.1 & 0.9 & -0.5 & 0.9 & 0.9 & 1 & 1 & 0 & 0 & 0.9 & 0 & 0 \\
\hline 1998 & 1.3 & 0 & 1 & 1.4 & 0 & 0.8 & 1 & 1 & 1.6 & 0 & 0 & 1 \\
\hline 1999 & 1 & 0.9 & 1 & 1.4 & 0 & 0.8 & 1 & 1 & 1.6 & 0 & 0 & 1 \\
\hline 2000 & 0.8 & 0.7 & 1.5 & 1.2 & 1.5 & 1.7 & 0 & 1.3 & 1 & 0 & 0.7 & 0.8 \\
\hline 2001 & 0.9 & 0.6 & 0.8 & 1 & 1.3 & 0.6 & 0.6 & 1.1 & 0.9 & 0 & 0.6 & 1 \\
\hline 2002 & 1.1 & -0.5 & 1.3 & 0.8 & 1.1 & 1 & 0.7 & 0.8 & -0.5 & 1 & 0.7 & 1 \\
\hline 2003 & 0 & 0.6 & -0.5 & -0.5 & 0.6 & 1 & 1 & 1.4 & 0 & 0 & 0 & 0 \\
\hline 2004 & 0 & -0.6 & 0.8 & 1.1 & 0 & 1.1 & 1 & 1 & 1.1 & 0.9 & 1 & 1 \\
\hline 2005 & 1 & 1 & 1.1 & 1.1 & 1.3 & 0.9 & 1.1 & 1 & 0.9 & 0.9 & 0.4 & 0 \\
\hline 2006 & 1.2 & 0.8 & 1 & 0.7 & 0.9 & 0.9 & 1.2 & 0.9 & 0 & 0 & 0 & 0 \\
\hline 2007 & 0.8 & 1.1 & 0.8 & 1.1 & 1.2 & 0.5 & 0.8 & 1.5 & 0.8 & 0 & 0 & 0.9 \\
\hline 2008 & 0.4 & 1.3 & 0.9 & 0.6 & 1.7 & 0.7 & 0.6 & 1.4 & 0.7 & 0.9 & 0.9 & 1.1 \\
\hline 2009 & 1 & 0.8 & 0 & -0.5 & 1 & 1 & 1 & 1 & 0.9 & 0 & 1.1 & -0.5 \\
\hline 2010 & 1.7 & 3 & 1 & 1 & 0.9 & 0.9 & 0 & 0.9 & 0.9 & 0.7 & 0 & 0 \\
\hline 2011 & 0.9 & 0.9 & 0.9 & 1.1 & 1 & 0 & 1 & 0 & 0 & 1 & 1.3 & 0.9 \\
\hline 2012 & 0.9 & 1 & 0.9 & 1.1 & 1 & 0.9 & 0.9 & 0.9 & 1 & 1.1 & 0.9 & 0.9 \\
\hline 2013 & 0.6 & 0.9 & 0.9 & 0.6 & 0.9 & 1.3 & 1 & 0.9 & 1.1 & 1.3 & 1.6 & 1.1 \\
\hline 2014 & 0.9 & 0.6 & 1.3 & 1.1 & 0.9 & 0.9 & 1.1 & 0.7 & 1.3 & 0.8 & 1.6 & 1 \\
\hline 2015 & 1.4 & 1.5 & 1.4 & 1.7 & 1.1 & 1.3 & 1 & 1.4 & 1.6 & 1 & 3 & 0.7 \\
\hline 2016 & 0.7 & 1.3 & 1.6 & 1.6 & 1.3 & 1.3 & 0 & 1.3 & 1 & 0.9 & 1.1 & 1 \\
\hline 2017 & 0.7 & 0.9 & 1.1 & 1.1 & 1.6 & 1.6 & 1.3 & 0.9 & 1 & 0.8 & 1 & 1.4 \\
\hline 2018 & 1 & 0 & 0.9 & 1.1 & 1.1 & 1.1 & 1.1 & 0.8 & 0.9 & 0.7 & 0.9 & 1.3 \\
\hline
\end{tabular}

and $-90 \mathrm{~W}$. The South Atlantic Anomaly, characterized by these coordinates, indicates a domain with the lowest magnetic field that is dependent from the Solar Cycles maxima and minima (1996-2018).

As recently established, the Van Allen belts receive ionized particles from two sources: 1) in the poles by magnetic reconnection in the dayside and 2) by the reconnection at the night side when there is a rupture of the magnetic lines and ionized particles are launched inside the Van Allen belts.

The only questionable area is the South Atlantic Anomaly, when the ionized particles hit a weaker field created by the internal dynamo misalignment. These particles are unable to be trapped by the weaker field, eventually being released through plasma instabilities to the Earth's surface. The questions here are: Are the variations in the density of the anomaly able to cause disturbances on the Earth's surface? Are these disturbances able to affect seismologic events? The answer depends on the earth's crustal surface and the tectonics in the area. At 
first, it seems that the location under the South Atlantic Anomaly with more seismic variations is situated at the shorelines of South America, between Peru and Chile. The triple junction is highly active during the period searched.

For this part of this study, we are using the calculations performed in section 2 to search the variations in earthquakes in the area defined by $0 \mathrm{~N},-50 \mathrm{~S}, 40 \mathrm{E}$, and $-90 \mathrm{~W}$. Scrutinizing the data from the perspective of Solar Cycles, the years of peaks, 2000 and 2014, did not show significant variations. Instead, significant variates occurred during a minimum, as in 2010, and one year after 2014 (maximum) in 2015. Actually, the years of minima, 2003 and 2010, showed more prominent negative anomalies and also higher positive disturbances.

\section{Data Discussion by Seasons}

With the datasets in Table 4 and Table 5, we can construct the next plots for seismic event variation during seasons [14]. Figures 4-7 are season variations for earthquakes with magnitudes M3 or higher, all depths, during 1996 to 2018.

Spring-The highest anomaly occurred in Sep (2015), around 2.3 times the average in the period analyzed. The negative anomaly happened in Nov (2010).

Summer-The highest anomalies occurred in Feb (2010) when the intensity of earthquakes reached four times the average. In the same period, there occurred three negative irregularities Dec (1999, 2010), Jan (2010), and Feb (2014). The years of solar maxima, 2000 and 2014, did not enhance the events.

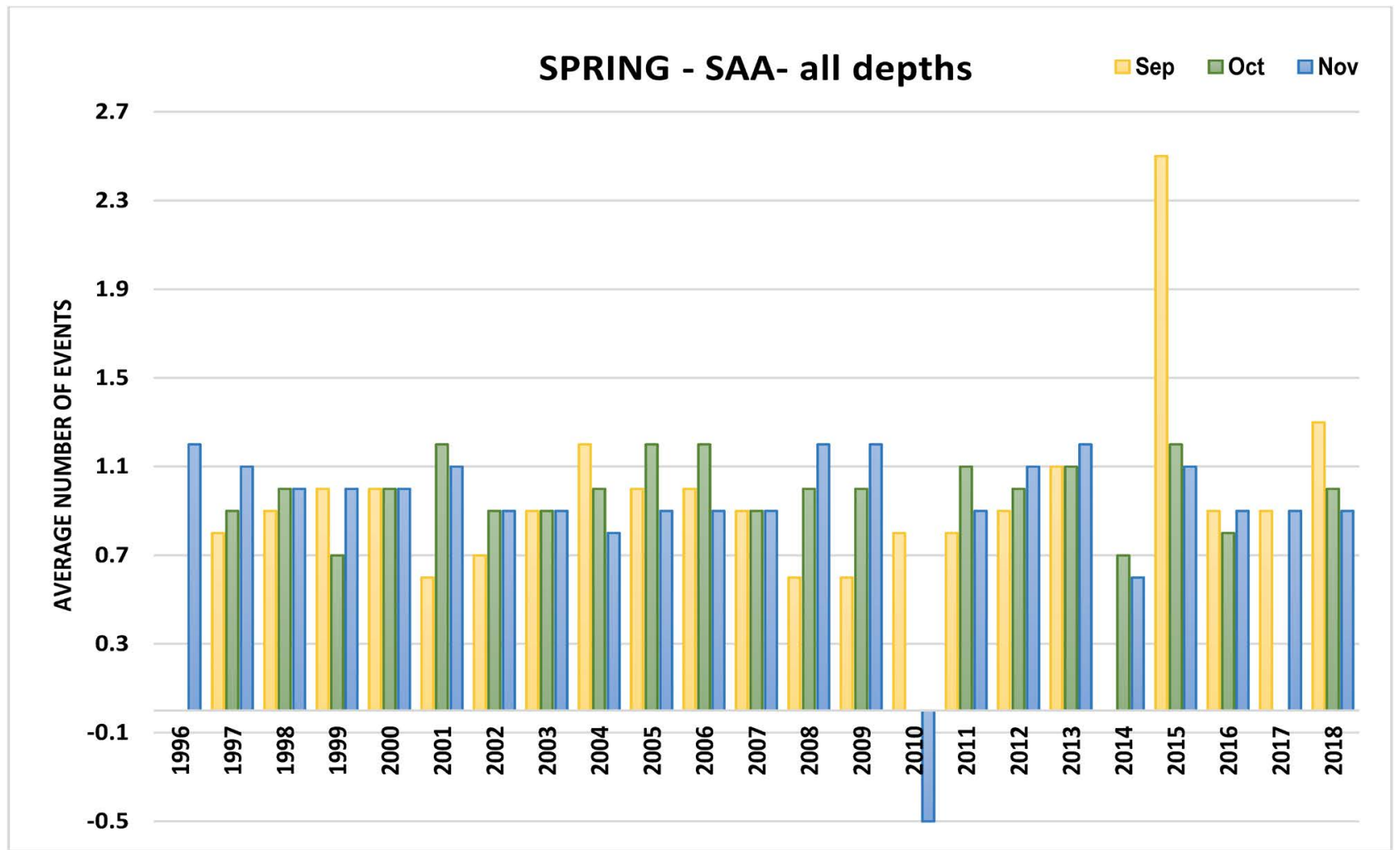

Figure 4. Earthquakes evolution Spring during two Solar Cycles. The y-axis means the average number of events variations. It is the same axis Figures 4-11. 


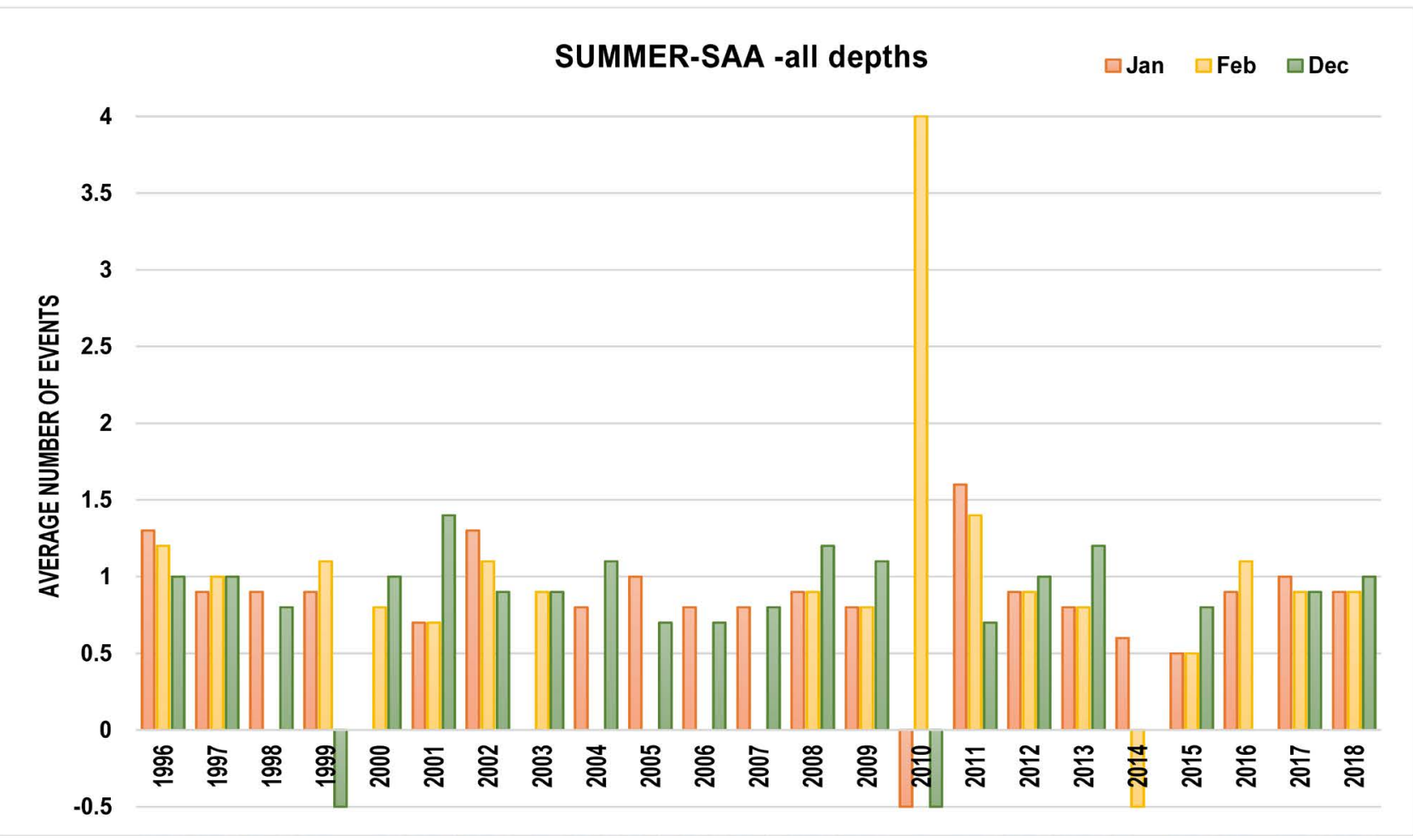

Figure 5. Earthquakes during Summer evolution during two solar cycles.

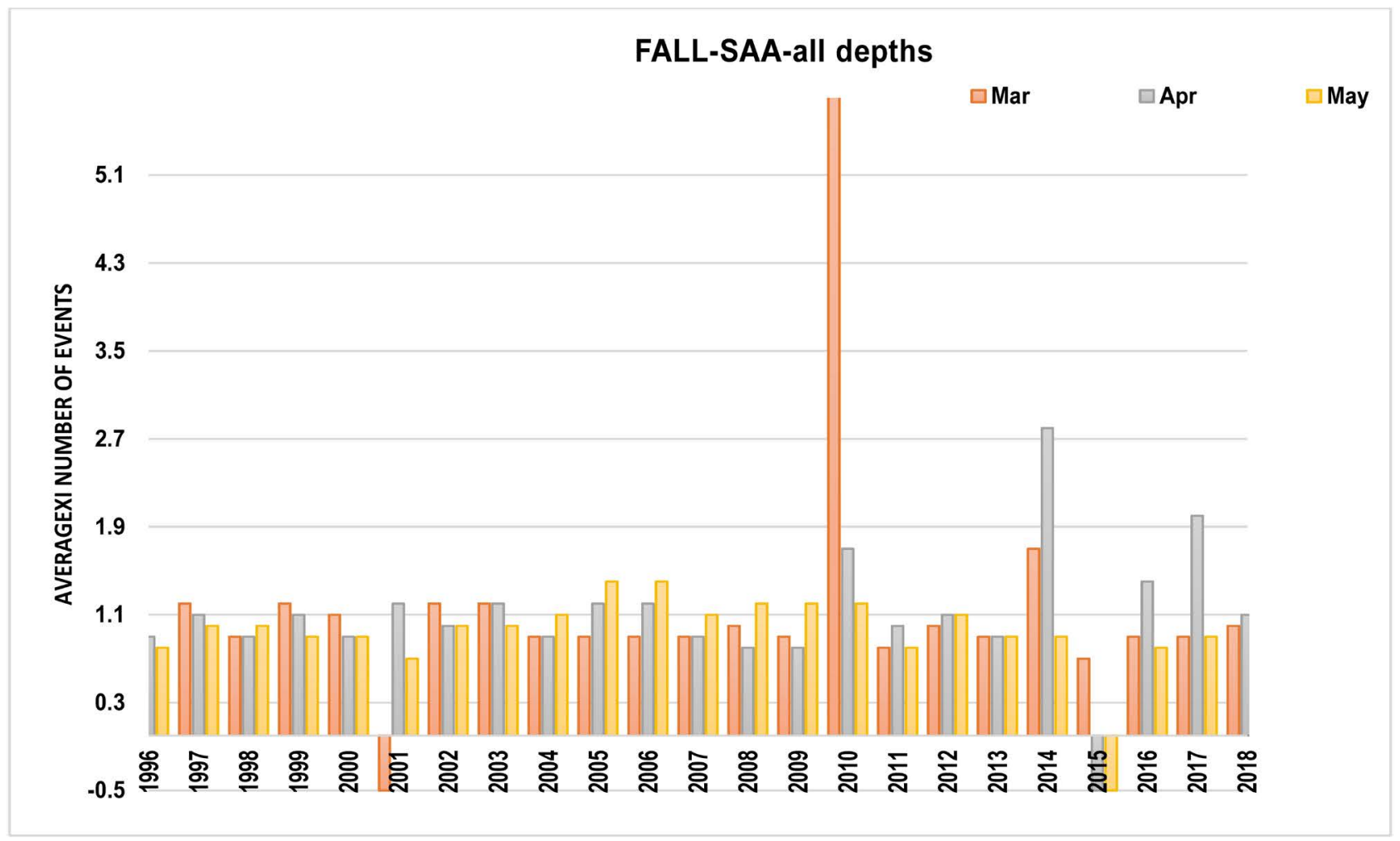

Figure 6. Evolution of earthquakes on two Solar Cycles during Fall. 
2

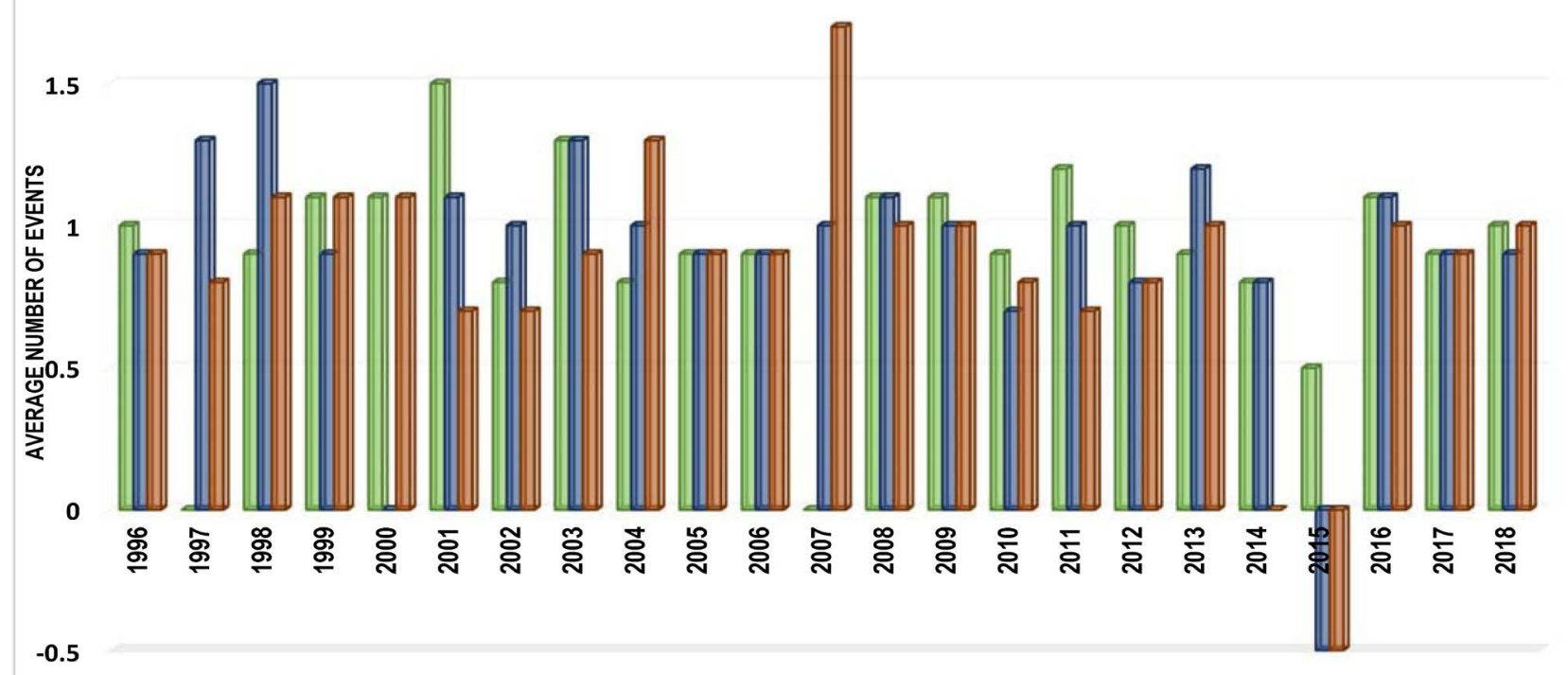

Figure 7. Evolution of earthquakes for all depths, two cycles, Winter.

Fall-The highest positive anomaly for all seasons and years occurred in Mar (2010) when it became 5.5 times the average. Negative points occurred in Mar (2001) and Apr and May (2015). During the years of maximum, 2000 and 2014, the peak of events happened in Apr (2014).

Winter-The enhancement of events occurred in Aug (2007), with the highest number of occurrences. The lowest anomalies in July and Aug (2015). Nevertheless, it is the season that had the weakest variations in the period searched.

\section{Discussions on Seasons for All Depths}

In comparing the dataset for Spring, Summer, Fall, and Winter, we find Fall has the highest anomalies in the period 2010-2017. For the seasons when this occurred, there was an increase in events during Summer-Fall and a decrease during Winter. For the Summer of Feb (2010), the positive anomaly was four times the average of events. For the Fall of March (2010), the positive irregularity was five times the average.

\section{Seasonal Variation for Depths $>200 \mathrm{~km}$}

Figures 8-11 show the seasonal variations for events with depths $\geq 200 \mathrm{~km}$.

Spring-The enhancement of earthquakes was in Nov (2015), while negative anomalies happened in Nov (1996) and September (2002).

Summer-Positive anomalies occurred in Feb (2010). Negative variances were more frequent and happened in Feb (2002, 2004), Jan (2003), and Dec (2009). 


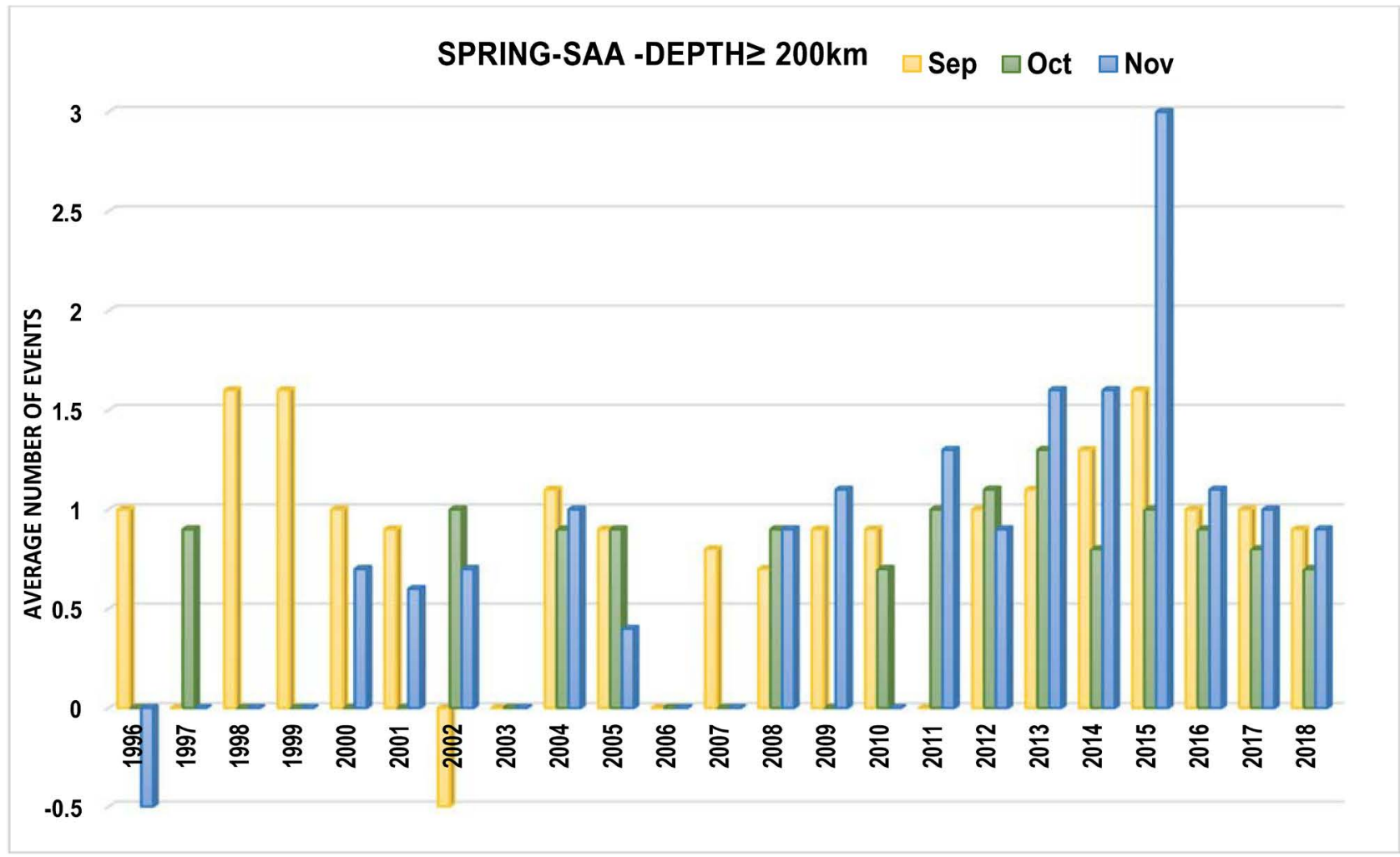

Figure 8. Evolution of Earthquakes two solar cycles, depths $\geq 200 \mathrm{~km}$ (Figures 8-11), Spring.

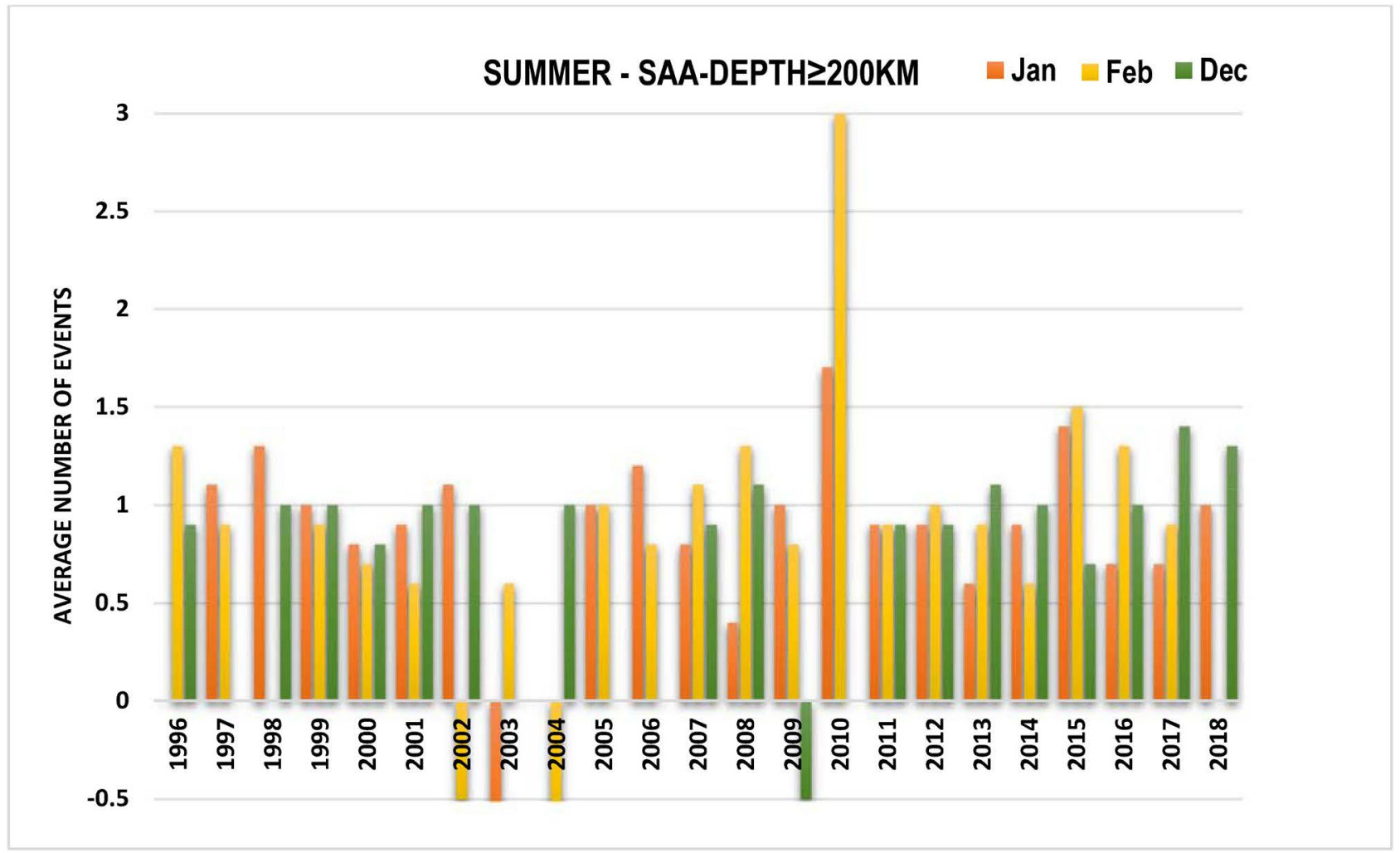

Figure 9. Development of earthquakes, two solar Cycles, Summer. 


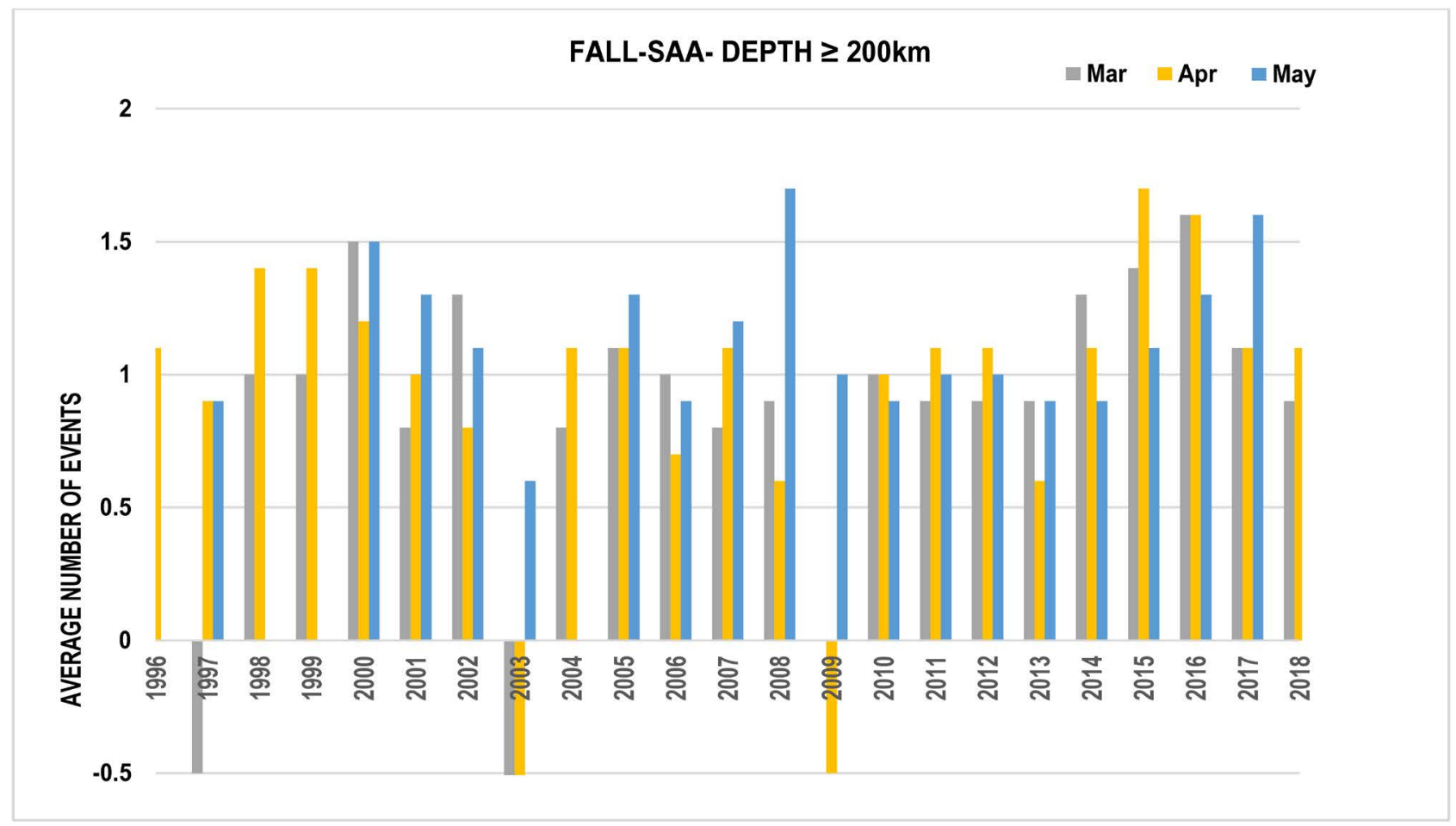

Figure 10. Evolution of earthquakes during two Solar Cycles, Fall.

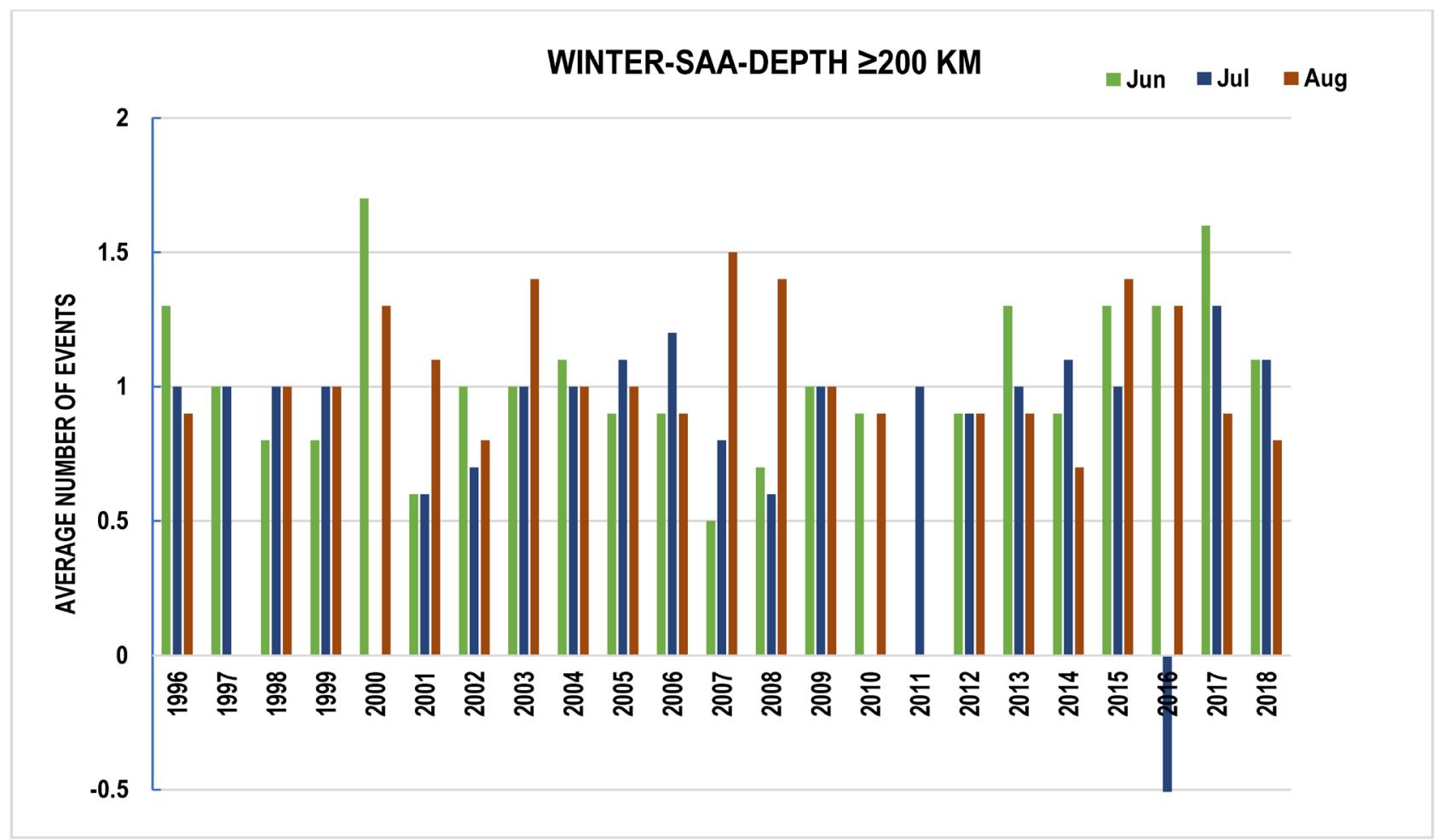

Figure 11. Evolution of events during two solar cycles, Winter. 
Fall-Positive anomalies happened in May (2008) and April (2015). Negative anomalies occurred in Mar (1997), Mar and Apr (2003), and Apr (2009). Any increase in earthquakes during this season was smooth.

Winter-There were the highest positive disturbance in 2000 (Jun), and negative in 2016 (2016). During the winter, June, July and August all the positive tremors anomalies were below two, in the period searched.

\section{Discussions on Seasons for Depths $>200 \mathrm{~km}$}

Comparing the datasets for Spring, Summer, Fall, and Winter for depths $>200$ $\mathrm{km}$, we find an increase below three, for any season. There were two exceptions during Spring and Summer during Nov (2015) and Feb (2010).

For the Fall and Winter, the earthquakes did not reach an increase above two. However, Fall, for this depth, presented four negative anomalies; these variations occurred for the years of minima in 1997, 2003, and 2009. This was similar to Summer, but different years, 2002 and 2009. Overall, the investigation of the activity pointed out that the period 2000 to 2009 had significance for number variation in the plots.

\section{Conclusion}

Our research follows the evolution of earthquakes during two Solar Cycles (23 and 24). We found that the Solar Minima was the period when earthquakes presented more variations between 2002 and 2010. The same search for the seasons pointed out that the seasons with more occurrences of earthquakes are Summer and Fall. Some of the data available for the deepest earthquakes also pointed to an uneven lithosphere as what makes the phenomena not well related to the Solar Cycles for those found to all depths. Overall, the South America Anomaly region does not present as many events as other locations around the Ring of Fire in the Pacific.

\section{Acknowledgements}

I am grateful to the anonymous publishing supervisor who made valuable suggestions to this paper.

\section{Conflicts of Interest}

The authors declare no conflicts of interest regarding the publication of this paper.

\section{References}

[1] Hudson, M.K., et al. (2008) Relationship of Van Allen Radiation Belts to Solar Wind Drivers. Journal of Atmospheric and Solar-Terrestrial Physics, 70, 708-729. https://doi.org/10.1016/j.jastp.2007.11.003

[2] Nasuddin, K.A., et al. (2019) Characterization of the South Atlantic Anomaly. Nonlinear Processes Geophys, 26, 25-35. https://doi.org/10.5194/npg-26-25-2019

[3] Aisikinen, T. and Mursula, K. (2005) Filling the South Atlantic Anomaly by Ener- 
getic Electrons during Great Magnetic Storm. Geophysical Research Letters, 32, L16102. https://doi.org/10.1029/2005GL023634

[4] Shaefer, R.K., Paxton, L.J., Selby, C., Ogorzalek, B., Romeo, G., Wolven, B. and Hsieh, S.Y. (2016) Observation and Modeling of the South Atlantic Anomaly in Low Earth Orbit Using Photometric Instrument Data. AGU Publications, Space Weather, 330-342. https://doi.org/10.1002/2016SW001371

[5] McCracken, K.G and Beer, J. (2014) Comparison of the Extended Solar Minimum of 2006-2009 with the Spoerer, Maunder, and Dalton Grand Minima in Solar Activity in the Past. Journal of Geophysical Research: Space Physics, 119, 2379-2397. https://doi.org/10.1002/2013JA019504

[6] Domingos, J., Jault, D., Pais, M.A. and Mandea, M. (2017) The South Atlantic Anomaly throughout the Solar Cycle. Earth and Planetary Science Letters, 473, 154163. https://doi.org/10.1016/j.epsl.2017.06.004

[7] USGS. https://earthquake.usgs.gov/earthquakes/search/

[8] IRIS. http://iris.edu

[9] https://spaceplace.nasa.gov/solar-cycles/en

[10] Hagen, M. (2015) Mechanism of Intraplate Earthquakes and the Anthropogenic Causes in USA. Natural Science, 7, 459-474. https://doi.org/10.4236/ns.2015.79047

[11] Hagen, M. and Azevedo, A. (2018) Possible Connections between Seasons and Ultra-Deep Earthquakes Worldwide. Natural Science, 10, 208-302. https://doi.org/10.4236/ns.2018.107029

[12] Hagen, M. and Azevedo, A. (2018) Deep and Ultra-Deep Earthquakes Worldwide, Possible Anomalies in South America. Natural Science, 10, 199-213. https://doi.org/10.4236/ns.2018.106022

[13] Hagen, M. and Azevedo, A. (2018) Seasonality and Tectonic Influences on Subduction Zones for Ultra-Deep Earthquakes. Open Journal of Earthquake Research, 7, 269-284. https://doi.org/10.4236/ojer.2018.74014

[14] Hagen, M. and Azevedo, A. (2018) Seasonality Variability and Periodicities for U1tra-Deep Earthquakes Worldwide. Open Journal of Earthquake Research, 8, 1-18. https://doi.org/10.4236/ojer.2019.81001 